\section{Neurn denenerative \\ Diseases}

Barker, R.A. 79

Braun, E.K. 93

Foerde, K. 93

Gluck, M.A. 102

Herzallah, M.M. 102
Kehagia, A.A. 79

Kéri, S. 72

Moustafa, A.A. 102

Nagy, H. 72

Nirenberg, M.J. 63

Robbins, T.W. 79
Shohamy, D. 93

Szamosi, A. 72

Weintraub, D. 63

\title{
Subject Index Vol. 63, No. 2, 2013
}

Acetylcholine 79

Basal ganglia 102

Catechol-O-methyl-transferase 79

Caudate nucleus 72

Compulsive behavior 63

D3 receptor 63

Delay discounting 72

Delayed feedback 93

Dementia 79

Dopamine 79

- agonist(s) 63, 102

- - withdrawal syndrome 63

- dysregulation syndrome 63

Dopaminergic medication 93

Dual syndrome hypothesis 79
Episodic memory 93

Executive function 79

Feedback-based learning 93

Fronto-striatal dysfunction 79

Hippocampus 93

Impulse control disorder 63

Impulsive-compulsive behavior 63

Impulsivity 72

Incremental learning 93

Levodopa 102

Memory function 93

Mesocorticolimbic 63
Noradrenaline 79

Overdose 79

Parkinson's disease 63, 72, 79, 102

Pathological gambling 63

Prefrontal cortex 102

Punding 63

Reinforcement 102

Reward 72

Stimulus-response learning 102

Striatum 93

$\alpha$-Synuclein 72

Working memory 102

\section{KARGER}

(C) 2012 S. Karger AG, Basel 